\title{
UMA ANÁLISE DO GÊNERO DO DISCURSO/DRAMATIZAÇÃO
}

\author{
NEILTON FARIAS LINS ${ }^{1}$
}

\begin{abstract}
This study intends to analyze discursive marks in the gender discursive dramatization. Such a study bases on the theories proposed by Bakhtin (1992), Halliday (1885), Koch (1993), Marcuschi (2003), Rojo (2004), Schneuwly (1997), Dolz (1997), Castilho (1998), which share the idea, that the man transforms the world through the use of the language.
\end{abstract}

KEYWORDS: Text. Language. Discursive Genders.

\section{INTRODUÇÃO}

Estudar a língua compreende anteriormente distinguir as postulações teóricas em que os lingüistas se baseiam atualmente, nos estudos de gramáticas. Há pelo menos três grandes vetores teóricos a serem seguidos segundo Castilho (1998, p.24) que são: inatismo (a língua como atividade mental), estruturalismo (a língua como atividade ou modelo estrutural de gramática), e finalmente o sociointeracionismo (a língua como uma atividade social), concepção na qual foi baseada nossa pesquisa.

Castilho (op.cit.) diz que, nessa última teoria, o homem veicula informações, externa sentimento, age sobre outro (homem). O sociointeracionismo está vinculado à gramática funcional e dentro deste aspecto estão as funções da linguagem ou metafunções definidas por Halliday (1994b). A elas estão relacionadas todas as probabilidades de opção semântico-lingüísticas plausíveis para um interlocutor em circunstância de intercâmbio com os outros ou com o mundo. São elas: a ideacional, a interpessoal e a textual. A metafunção ideacional faz referência à "expressão do conteúdo de acordo com a experiência do interlocutor inserido em uma comunidade de fala" (Halliday,1973:37); a metafunção interpessoal à "expressão das relações sociais e pessoais" dos papéis desempenhados nas interações; a metafunção textual ao "cumprimento das exigências de operacionalidade de uma língua" (op. cit.:42), ou seja, à construção e à organização da mensagem dentro de um sistema determinado pelo contexto e pela intenção do autor. ${ }^{1}$

\footnotetext{
1

Graduado em Letras pela FAMASUL (FACULDADE DE FORMAÇÃO DE PROFESSORES DA MATA SUL) e Especialista em Língua Portuguesa pela FAMASUL

Falaremos sobre isso depois, em um capítulo em que abordaremos um questionamento da língua como dicotômica ou práticas de uma mesma língua.
} 
${ }^{2}$ Por um lado a descrição funcional do idioma envolve identificações de todas as funções que estão incorporadas na gramática, e por outro lado todas as configurações diferentes pelas quais estas funções estão definidas - quer dizer, todas as possíveis estruturas que servem para expressar algum significado no idioma."(Halliday, 1994b:29-30).

Tal gramática estuda as funções sociais da língua. Este estudo parte do princípio de que toda aprendizagem é um processo contínuo, sujeito a mudanças decorrentes das transformações ocorridas no contexto social e histórico em que os indivíduos se encontram. A partir do contato estabelecido com o meio ambiente e com seus semelhantes, o homem adquire informações, desenvolve habilidades e estabelece valores (Oliveira, 1999).

O principal objeto de estudo da Gramática Funcional é o texto oral ou escrito, entendido como um produto autêntico de uma interação social, parte de um contexto cultural e social. Dessa forma, o processo de ensino-aprendizagem é fundamentalmente social e histórico, pois sua constituição está sujeita às influências de fatores externos ao indivíduo. O interacionismo sócio-discursivo constitui a base teórica sobre a qual está calcado o presente estudo, e atribui à linguagem e à interação o papel de instrumentos essenciais na construção do conhecimento e na formação dos indivíduos. O homem socialmente age e interage com o outro através da língua, para expressar para alguém que o ama, para dizer que o odeia, para fazer uma receita de bolo, uma lista de compra, discursar em uma formatura, congresso, seminário, palestra, comício político, enfim é através da língua que o homem se comunica com o seu interlocutor, assim, cabe a nós estudarmos estas duas categorias da língua, a escrita, que é de certa forma fixa e falada mais renovável, dependendo do contexto social de sua produção. Embora, segundo Marcuschi (2003) "a língua não seja dicotômica", ou seja, essa divisão não confere duas modalidades lingüísticas, como querem dividir alguns teóricos, mas práticas diferentes da mesma língua.

Nessa perspectiva desejamos analisar as marcas discursivas no gênero do discurso/dramatização apresentada pelos alunos de uma $8^{\underline{a}}$ série do ensino fundamental em Novo Lino.

\section{TEXTO E DISCURSO}

Ligando a noção de texto à de contexto, Halliday (em Halliday e Hasan, 1985) define texto da maneira mais simples possível, como avalia o próprio autor, como "língua ou linguagem que é funcional" (Halliday op. cit. p. 10). Por funcional, Halliday entende língua que está prestando algum serviço em algum contexto. Assim, um texto pode ser tanto falado quanto escrito, ou em qualquer outro meio (medium) de expressão. Para ele, texto e contexto são aspectos do mesmo processo; não devem ser separados. O autor explica que o contexto sempre precede o texto, e a situação é anterior ao discurso que se relaciona com ela. É partindo do contexto da situação que o ser humano é levado a um dos fatores que contribuem para uma boa compreensão: a predição.

De acordo com o autor, o importante não é pensarmos no texto como sendo composto por palavras ou sentenças, mas sim por significados. É evidente que esses significados têm que ser expressos, ou codificados em palavras e estruturas, sons ou

Tradução nossa 
símbolos, para que possam ser comunicados, mas, para ele, um texto é essencialmente uma unidade semântica.

Para Halliday, assim como para outros autores, como veremos mais adiante, a noção de texto está diretamente ligada à de discurso, uma vez que o discurso se manifesta através de textos. As noções de texto e discurso estão, por outro lado, ligadas a dois outros conceitos igualmente importantes, em torno dos quais toda a discussão dos autores aqui resenhados irá girar: o de "função lingüística" e o de " função social" . Vale, portanto, mostrarmos como essas funções são definidas. Segundo Halliday (op. cit.), "função da língua" (ou "função da linguagem" ) constitui-se em: "...componentes funcionais do sistema semântico de uma língua.” (Halliday, op. cit. p.29).

Os três componentes funcionais (ou "metafunções") postulados por ele são:

componente ideacional, subdividido em lógico e experiencial ("experiential"); corresponde ao que se costuma chamar de função cognitiva ou referencial e está ligado ao campo do discurso ("field of discourse" );

componente interpessoal, que é a função da língua no processo de interação social; está ligado aos participantes da interação (ao "tenor of discourse" ); componente textual, refere-se a todas as características e elementos (semânticos; gramaticais; estrutura temática; foco de informação; etc.) que tornam possível a adequação de um texto a um determinado contexto; está diretamente ligado ao "modo" do discurso ("mode of discourse").

Halliday enfatiza que a língua é multifuncional; todos esses componentes e funções estão interligados ${ }^{2}$.

\footnotetext{
"Os significados são tecidos junto em um tecido muito denso de tal um modo que, para os entender, nós não olhamos separadamente para suas partes diferentes; bastante, nós olhamos simultaneamente para a coisa inteira de vários ângulos diferentes, cada perspectiva que contribui para a interpretação total. Isso é a natureza essencial de uma aproximação funcional." (Halliday, em Halliday e Hasan, 1985, p. 23).
}

Como já foi apontado, o autor trata a análise da língua sob um ponto de vista social, fazendo ligação entre a língua e a estrutura social e conceituando-a como um dos vários conjuntos de sistemas de significados - ressaltando sua exterioridade semiótica (formada por signos) - da cultura do homem. Halliday expõe com nitidez sua inquietação com as afinidades entre a língua e a estrutura social, ponderando a estrutura social como um aspecto do sistema social.

Outros teóricos, amparado em Halliday, tratam e definem também os vocábulos Texto e Discurso, evidenciando também apreensão com o social e com a conjuntura de produção ou circunstância de conversação. Koch. (1987) assegura que os termos texto e discurso podem ser aceitos em duas significações: no sentido lato e no sentido estrito. No sentido lato, o termo texto refere-se "a qualquer tipo de comunicação realizada através de um sistema de signos" (Koch, 1987, p. 21). Neste sentido, um texto pode ser qualquer manifestação de comunicação, por meio de uma música, de uma pintura, de um romance, etc. Já no sentido estrito, um texto incide "em qualquer passagem falada ou escrita, capaz de formar um todo significativo, independentemente de sua extensão." (Koch, op. cit. p. 22).

$2 \quad$ Traduzido por nós. 
No que se refere ao termo discurso, a escritora conceitua-o, no sentido lato, como atividade comunicativa de um locutor, numa situação de comunicação determinada, conglomerando não só a definição de enunciados por ele produzidos em tal circunstância - ou os seus e os de seu interlocutor, no caso do diálogo - como também o evento de sua enunciação."(Koch, op. cit. pp. 21 e 22). A referida escritora defende que o discurso dá-se de forma lingüística, no sentido estrito, através de textos, dessa forma, é capaz de ser acentuado como "uma integração semânticopragmática, de um contínuo comunicativo textual que se distingue, entre outros fatores, pela coerência e pela coesão, conjunto de relações responsáveis pela organização do texto." (Koch, op. cit. p. 22).

Em Koch \& Travaglia (1990), é apresentada uma significação detalhadamente, em qual, além dos predicados prontamente apregoados na acepção de Koch indicado anteriormente, tais escritores ressaltam uma ulterior especialidade importante: a função de capaz de produzir comunicação do texto além da condição de intercâmbio comunicativo. Esses defendem, também, a tema coerência dentro do texto, que se reflete diretamente na lógica discursiva. Para eles, é a coerência que faz com que um encadeamento lingüístico qualquer seja vista como um texto, uma vez que torna crível, através de múltiplos fatores, as relações sintático-gramaticais, semânticas e pragmáticas entre os elementos da seqüência (morfemas, palavras, expressões, frases, parágrafos, capítulos, etc.), consentindo que tanto sua construção quanto sua recepção se constituam em uma coesão significativa global. Asseguram que é a coerência que dá textura ou textualidade, abrangendo os termos "textura" ou " textualidade" como " aquilo que transforma uma seqüência lingüística em texto" (Koch \& Travaglia Op. Cit. p. 45).

Igualmente como Halliday, Koch (op. cit.) acredita também que o ser humano utiliza a linguagem para interação social através de seu discurso. A linguagem é ponderada por essa teórica como um formato de ação sobre o mundo, carregado de intenções, vista como veiculadora de sistema de idéias e distinta pela argumentatividade. A escritora afirma ainda, que a argumentação, inscrita no uso da linguagem, constitui-se em uma atividade que estrutura um determinado discurso. Logo, Tanto Halliday quanto Koch e Kock e Travaglia dão ênfase ao caráter social do texto e do discurso, compartilhando inclusive, o conceito de que um não pode estar desvinculado do outro.

Dessa forma, defendemos que não é admissível discorrer sobre texto e sobre discurso sem discorrer de igual modo sobre gênero. Não são exclusivamente as definições de texto e de discurso que se arrolam diretamente, da mesma forma conceito de gênero está relacionado aos ulteriores. Independentemente do tipo de abordagem ou escola, adotados nos diversos estudos deparados na literatura, o nome de gênero permanecerá continuamente relacionado ao de discurso, e este ao de texto. Assim, um não terá existência sem o outro.

Para Swales (apud Santos, 1996), um gênero incide em uma ocorrência comunicativa, com finalidades operacionais (comunicativos) bem definidas, que são compartilhados e compreendidos por membros da comunidade discursiva na qual e para a qual aquele evento será realizado.

\section{GÊNEROS DO DISCURSO / LÍNGUA FALADA E ESCRITA}


Segundo Lins $(2007,02)$ :

A palavra "gênero" sempre foi bastante utilizada pela retórica e pela literatura com acepção designadamente literária. Segundo Todorov (1978), essa palavra tem sido usada desde Platão, cujo objetivo era distinguir o lírico, em que apenas o autor falava, o épico, em que o autor e personagem falam, o dramático,em que apenas a personagem falava. Brandão (apud Santos, 2004) dizia que o estudo de gêneros foi uma constante temática, interessa aos antigos... tanto na retórica quanto às pesquisas em , semiótica literária e teorias lingüísticas.

Os gêneros aparecem na perspectiva da fala e da escrita dentro de um continuum, tipologia das práticas sociais de produção textual. Nessa perspectiva, nos embasaremos em Bakhtin (1992/1979/), Marcuschi (2003), Rojo(2004), Schneuwly e Dolz (1997), dentre outros teóricos. Optamos pelos teóricos os quais, a discussão relativa à língua falada e escrita não toma posição favorável à dicotomia. Marcuschi (2003. p. 17) diz que a oralidade e a escrita são práticas e uso da língua característica própria, mas não tão suficiente oposta para caracterizar dois sistemas lingüísticos, Ramos (1997) tem a mesma concepção quando assume que a correlação entre fala e a escrita está num continuum das práticas sociais.

\section{HISTORICIDADE DA LÍNGUA FALADA E ESCRITA}

Estas duas vertentes, que sejam elas, a língua escrita (L.E) e a língua oral (L.O) são objetos de pesquisa de diversas dissertações de mestrado e teses de doutoramento, sobretudo, tem sido assunto discutido em congresso, palestras, mesas redondas, artigos científicos e livros afins, o que ocasiona grande circulação de trabalhos nessa área cientifica. esmo assim, gostaríamos de tecer alguns comentários ou dizer algumas palavras que estejam relacionada com a historicidade dessas duas modalidades.

Alguns teóricos defendem que a língua escrita tem supremacia sobre a língua oral, visto que as pessoas que desenvolveram a escrita ou possuem a capacidade escrever são mais civilizados do que os que não escrevem, ou seja, que não escreve é anti-social ou sem cultura. Tal conceito é de certa forma irônico, tendo em vista que, quem dá ordem de liberar um vírus antrax, do Ébola, uma bomba atômica, dentre outros males que afetam a humanidade, são exatamente os "civilizados". O que percebemos na verdade é um certo grau de preconceito de alguns estudiosos com relação à modalidade oral.

O uso da L.E é muito recente em comparação a L.O isso pelo fato de nos nossos primórdios os homens muito pouco usavam essa modalidade, visto que a L.O foi adquirida por processo de seleção natural operando ao longo de um milhão de anos (Graff apud Marcuschi,2003). Passaram milhões de anos e os homens começaram a usar hieróglifos ou símbolos gráficos, escritos nas paredes das cavernas, nas pedras, etc, com a finalidade de representar algo, ou comunicar uma mensagem a alguém. Depois tais hieróglifos se transformaram em símbolos ou letras, cujo objetivo era representar a fala. ${ }^{3}$

3 O certo é que a escrita não representa a fala, seja de que ângulo for que a observemos Marcuschi (2003) 
Paralelo ao que temos dito sobre o fato de a origem da escrita datar de muito pouco tempo, Graff (apud Marcuschi, 2003) diz que a escrita surgiu há pouco mais de 3.000 anos a.C, enquanto que a espécie homo sapiens data de cerca de milhões de anos a.C.

O autor citado, anteriormente, revela que a história da humanidade é muito fragmentada, ocultando alguns detalhes que seriam importantes para esclarecer certos pontos na história da fala e da escrita.

\section{QUESTÕES DA LÍNGUA ORAL \& ESCRITA: SIMILARIDADE OU DISPARIDADE}

Essas duas modalidades têm sido postas como contraditórias por muitos teóricos da linha tradicional, embora em um estudo mais aprofundado, dizemos que a oralidade e escrita são práticas sociais que possuem um mesmo objetivo: a comunicação.

Marcuschi define a oralidade como:

A oralidade seria uma pratica social interativa para fins comunicativos, que se apresentam sob variadas formas ou gêneros textuais na realidade sonora; ela vai desde uma realização mais informal à mais forma, nos mais variados contextos de uso.

Marcuschi (2003) diz, ainda, que não se pode investigar contundentemente as similaridades e disparidades entre F.E e L.O, sem levar em conta o uso na vida diária do usuário de uma língua, ou melhor seria impossível distinguir tais relações, se essa tentativa for baseada no código lingüístico, mas em vez disso focalizar essas modalidades com conjuntos de práticas sociais.

Há quem diga que a L.O tem primazia sobre a L.E pelo fato de primeiro o homem usar a L.E., visto que o homem é um ser que fala e não um ser que escreve. Paralelo a isso Marcuschi (2003) diz que:

A escrita não pode ser tida como uma representação da fala...porque a escrita não consegue reproduzir muitos fenômenos da oralidade, tais como a prosódia, gestualidade, os movimentos do corpo e dos olhos, entre outros .

A criança adquire a capacidade de falar naturalmente no cotidiano e contexto social em que estiver inserido, através dos diálogos, músicas que ouve e/ou programas televisivos que ouve e vê, dentre outros aspectos discursivos - embora seja uma forma natural de aprendizado, no entanto não deixa de ser uma rica inserção cultural e social, já a escrita é adquirida pela criança em contextos formais, isto é, será necessário que a criança freqüente uma sala de aula ou uma escola para aprender tal modalidade, baseado nesse principio a escrita é tida como prestigiosa com relação à oralidade, nesse aspecto essas modalidades são denominadas de práticas sociais da língua.

As relações existentes entre L.O e L.E não são evidentes por si mesmas, nem seguem um padrão simples, visto que elas cogitam um imutável dinamismo fundado num continuum que se manifesta entre essas duas modalidades de uso da língua. Postular superioridade da modalidade escrita sobre a modalidade oral seria um ponto de vista um tanto controverso entre ambas, visto que não podemos dizer que haja superioridade entre ambas, isto é, seria interessante levar em conta que aspecto 
estaria sendo comparado e como diz Marcuschi (2003) essa relação não homogênea nem constante. O autor citado acima diz:

... as diferenças entre a fala se dão dentro do continuum tipológico das práticas sociais de produção textual e não na relação dicotômica de dois pólos opostos...Isto equivale dizer que tanto a fala como a escrita apresenta um continuum de variações, ou seja a fala varia e a escrita varia. Assim, a comparação deve tomar como critérios básicos de análise uma relação fundada no continuum dos gêneros textuais para evitar as dicotomias estritas.

\section{LÍNGUA ORAL E ESCRITA: DICOTOMIA OU PRÁTICAS DE UMA MESMA LÍNGUA?}

A visão que se tem da análise das relações existentes entre as duas modalidades de uso da língua (fala versus escrita), e que á língua apresenta características dicotômicas, isso vista pela maior parte das concepções teóricas da lingüística, Marcuschi (2003) enfatiza isso muito bem quando diz:

De um lado, temos teóricos como Bernstein (1971), Labov (1972), Halliday (1985, uma primeira fase), Ochs(1979), representantes das dicotomias polarizadas e visão restrita. De outro lado temos outros autores como Chafe (1982, 1984, 1985), Tannen (1982,1985), Benveniste (1990), Halliday/Hasan(1989) que percebe a relação entre fala e escrita dentro de um continuum, seja tipológico ou da realidade cognitiva e social.

A dicotomia defendida pelo primeiro grupo de lingüistas se volta basicamente para o código e ficam inerentes aos fatos lingüísticos. Tal dicotomia foi precursora das normas gramaticais ou prescritivismo de uma única norma lingüística, tida como padrão, isto é, a que originou hoje o que chamamos de uma norma padrão; como também originou dois pólos distintos numa mesma língua, quando atribuiu diferença entre a L.O e L.E.

Dessa forma, Marcuschi (2003) defende que tais dicotomias são frutos de uma observação empírica de uso da língua e não de características dos textos produzidos. A dicotomia estrita está muito presente nos livros didáticos, cujos autores têm uma concepção de língua estruturalista, isso pelo fato de essa tendência andar de braços dados com o estruturalismo, o que por sua vez vê o ensino da língua como um ensino de regras gramaticais.

Já a visão do segundo grupo é que não há dicotomia, paralelo a esse fato, vejamos algumas comparações faz Marcuschi (2003), entre essas duas vertentes:

B As semelhanças são maiores do que as diferenças tantos nos aspectos estritamente lingüísticos quanto nos aspectos sociocomunicativos (as diferenças estão mais na ordem das preferências e condicionamentos);

B As relações de semelhanças e diferenças não são estanques nem dicotômicas, mais contínuas ou pelo menos graduais (considerando-se que o controle funcional do continuo acha-se no plano discursivo);

B As relações podem ser mais bem compreendidas quando observadas no continuo (ou na grande) dos gêneros textuais (que em boa medida se dão em relações de contrapartes, ocorrendo, em grau significativo, gêneros similares nas duas modalidades); 
B Muitas das características diferenciais atribuídas a uma das modalidades são propriedades da língua (por exemplo, contextualização/descontextualização; envolvimento/ distanciamento);

B Não há qualquer diferença lingüística notável que perpasse o contínuo de toda a produção falada ou de toda produção escrita, caracterizando uma das duas modalidades (pois as características não são categóricas nem exclusivas);

B Tanto a fala como a escrita, em todas as suas formas de manifestação textual, são normatizadas ( não se pode dizer que a fala não segue normas por ter enunciados incompletos ou por apresentar muitas hesitações, repetições e marcadores não-lexicalizados;

Esse mesmo lingüista registra que a fala e a escrita são diferentes, mas a diferenças não são polares e sim graduais e continuas. São duas alternativas de atualização da língua nas atividades sócio-interativas diárias.

Conforme Marcuschi (2003), "As diferenças entre fala e escrita se dão dentro de um continuum tipológico das práticas sociais e não na relação dicotômica de dois pólos opostos." Assim, dentro desse continuum, seremos capazes de constatar que há textos escritos que têm mais proximidade ao pólo da conversação espontânea, como por exemplo acontece com o bilhetes e cartas familiares, enquanto que há outros textos falados que estão mais próximos aos do pólo da escrita formal, temos como exemplo conferências, palestras e entrevistas.

De forma que tanto a fala como a escrita percorrem um continuum que vai do nível mais formal ao informal, ou reciprocamente, atravessando graus intermediários. A escrita é tida como uma estrutura complexa, formal, sem dependência com o contexto, já a fala apresenta uma estrutura simples ou até mesmo sem estrutura, e de grande dependência do contexto em que está inserida. Devido a essas e outras peculiaridades, como por exemplo, a pausa, hesitações, truncamentos, a língua falada era até 1960 considerada como um lugar caótico.

Desde os aparecimentos das análises do texto falado, a ênfase foi dada na direção ao processo em si. De forma que, a linguagem usada no texto discursivo necessita de ser tida apenas como simples verbalização, carecendo ser analisada quando da análise textual as condições de produção. Os fatores que deveriam ser considerados constitutivos entre fala e escrita satisfazem apenas a diferenças estruturais.

Logo, ao ser feito uma análise sobre língua falada, é imprescindível analisar de que forma se instaura a conversação, gênero típico da língua falada. Assim dizemos que conversação é uma atividade iniciada de forma automático e livre na vida habitual, na maioria das vezes face a face, entre interlocutores que interagem através da linguagem alternadamente sobre determinado assunto em uma situação social e tempo específicos e reais. No diálogo, os interlocutores alternam seus papéis de falante e ouvinte, e por meio dessa atividade interativa deriva-se o texto conversacional, organizado numa determinada circunstância de comunicação. Notase que todo evento de fala ocorre num contexto situacional específico, compreendido como situação extralingüística, isto é, a ocasião confinante, o instante e as ocorrências em que tal episódio dar-se, abarcando os favoráveis compartes com suas peculiaridades especiais e os plausíveis elos que os prendem.

\section{A CONVERSAÇÃO E A LÍNGUA FALADA}


A conversão é uma atividade lingüística fundamental. Ela se associa ao fazer habitual de qualquer cidadão, isso, sem levar em contar qual o nível sócio-cultural que ele pertence, a conversão representa a relação verbal em que dois ou mais individuo se alternam, interagindo através da língua sobre objetos propiciados pela vida diária. Marcuschi (1986) comenta a conversação dizendo que a conversação é a primeira das formas da linguagem a que estamos expostos e provavelmente a única da qual nunca abdicaremos pela vida afora.

As matérias conversacionais são tão abundantes quanto gratuitas, visto que, a condição necessária para que haja conversação entre duas ou mais pessoas é que ambas manifestem interativamente desígnio de entrar em contacto ou ponderem sobre determinado assunto.

Castilho (1998) diz que ao averiguar a estrutura de produção da conversação, poderemos fazer a seguintes perguntas:

B O que leva as pessoas conversarem?

ß Quais são as rotinas estabelecidas em nossa cultura para a condução de uma conversa?

B Como se estabelece o jogo interpessoal no interior da conversação, isto é, quais são as regras sociais observadas nas práticas de alternância dos turnos conversacionais?

B Como se elabora o assunto na conversação?

B Que materiais lingüísticos são empregados habitualmente nas estratégias de iniciar, manter ou encerrar uma conversa?

B Quais são os "esquemas de poder" exemplificados pelos parceiros de uma conversação, nas táticas da argumentação e do convencimento?

ß Quais são os tipos de conversação.

Para responder tais perguntas esse autor afirma que, o professor precisa formular conjuntos de atividades para serem desenvolvidas, tais como: gravar conversa livre de alunos, pedir permissão a cada informante pelo uso desse material em aulas, transcrever o material coletado, examinar as transcrições formulando questões e fazer observações observando o caráter interacional, depois textual e por fim, não menos importante o gramatical. Para Koch (1992):

\footnotetext{
O falante assume para si o papel de falante em relação a um destinatário quando instaura um eu e projeta para o destinatário um você. Para que a interação aconteça o ouvinte deve ser capaz de reconhecer os papéis dêiticos instaurados, assumindo o falante como o eu e a si mesmo como você, até que, no caso da conversação, haja uma mudança de turnos e os papéis sejam invertidos.
}

Para manter o poder em certo turno, o falante utiliza estratégias para a manutenção do turno, tais como: pausas não muito longas, alongamento de vogais e consoantes, de artigos, conjunções e preposição, autocorreção, o locutor substitui o item lexical escolhido, ou muda o rumo da conversa, temendo ser corrigido pelo outro interlocutor e assim perdendo turno.

Uma passagem de um turno se dá por assalto ao por consentimentos do interlocutor, o assalto ao turno é um dos mais eficazes de um ouvinte, tendo em vista que nem sempre em uma conversa o interlocutor dá permissão ou passa a palavra para o ouvinte. Dessa forma, o ouvinte assalta o turno, usando interrupções, negando, 
afirmando, ou concordando com a fala do interlocutor. Um assalto bem sucedido acontece após uma "deixa" do interlocutor, em que o mesmo não passa o turno para o ouvinte, mas lhe dar oportunidade para que esse tome o turno, não quando a "deixa", mas também quando o interlocutor desiste do turno. Preti (1988) chamou essa desistência de sobreposição de vozes.

Há outras formas de passagem de turno de um interlocutor para o ouvinte, como por exemplo o olhar, visto que, em uma conversação as pessoas tendem a se olhar o mínimo possível, quando assim o fazem estão concedendo ao outro o direito de falar, ou seja, estão passando o turno para o outro. Outra forma é pausa na em uma seqüência lingüística, ou a queda rítmica, visto que uma seqüência lingüística gera a expectativa de outra seqüência. Se casualmente ouvinte não interagir o interlocutor retoma a interação. Outra forma de passagem é através dos marcadores conversacionais, tais como: não é mesmo? Tudo bem pra você? Ok? Valeu? Falô? e tantos outros que a língua nos permite usar. Em suma, a conversação é uma área muito vasta a ser explorada, tendo em vista que a conversa há por todos os lados, assim gostaríamos de salientar que análise do Corpus, desse trabalho, estará fundamentada na disciplina Análise da Conversação.

As tomadas e detenção de turno são caracterizadas por determinadas marcas, por exemplo: o detentor de turno pode favorecer condições para que um dos interlocutores possa interagir ou fazer assalto de turno, Koch (1998) pormenoriza dizendo que o atual detentor do turno pode eleger o falante seguinte, isso por meio de deixas realizadas através de marcadores conversacionais, tais como: que achas? $\mathrm{E}$ então? De acordo? Ta certo? Ficou claro? Entendeu? Dentre outros. Esses marcadores podem ser indicadores de finais, concordância ou discordância de segmentos de tópicos, a Analise da Conversação chama tópicos de aquilo sobre o que se fala,ou melhor, tem-se comprovado que os falantes elegem assuntos para falação, isto é, mesmo na língua falada que tende ser menos planejada, há sempre uma tendência para organizar o que se fala por tópicos ou assuntos.

Os turnos conversacionais amplamente analisados por Koch (1989) e Marcuschi (1986) definem-se como uma guerra pelo poder, guerra para manutenção e tomada do turno, visto que nem sempre um turno é passado para outro falante de maneira espontânea. Boa parte dessa tomada ou manutenção de turno se dá de maneira imposição por parte dos interlocutores envolvidos no discurso. Como diz Marcuschi (1986), na conversação (língua falada), os interlocutores são co-produtores do discurso, visto que colaboram um com o outro, co-negociando, co-argumentando o discurso. Há, porém situações que o detentor do poder passa o turno conversacional para o outro interlocutor, se esse não interage, qualquer outro envolvido no discurso poderá o fazer, mesmo assim se não houver quem o faça o turno volta para aquele que o tinha a princípio.

Koch (1989) diz que a tomada de turno pode acontecer, fora do momento previsto, a esse fenômeno como já tem sido exposto dar-se o nome de assalto ao turno, que acarretará em um outro fenômeno chamado de sobreposição de vozes, que é instante em que dois interlocutores falam subitamente ou de uma só vez ao mesmo tempo, o que pode acontecer de um dos envolvidos tomar realmente o turno ou desistir da tomada. 
Santos (1999) pondera que, em interações assimétricas, um interlocutor tem mais poder do que outro na interação. Essa mesma autora diz, ainda, que em situação de sala de aula, o discurso permite que o sentido do tópico seja negociado, o que pode ocasionar a imposição de argumentos por parte do que tem mais poder nas negociações discursivas.

Segundo Van Dijk (apud Santos 1999):

...o locutor que detém Poe usar estratégias para influenciar seus dominados, como caracterizar suas atitudes como altruístas e valorizar seus próprios interesses, o que tem levado esses dominantes à prática de autodefesa desses interesses, considerando-se inevitáveis, verdadeiros ou ponderáveis, quando qualificados como ruins pela maioria da população.

\section{GÊNERO DISCURSIVO DRAMATIZAÇÃO}

Antes de pensarmos dramatização, percorramos o conceito de gênero dramático estudado pela retórica e teoria literária e, assim, façamos um paralelo entre esse gênero retórico e o gênero discursivo dramatização. Para Infante(2001):

Como indica o próprio termo "dramático" (que provem do verbo grego drao, "fazer, agir"), a principal característica desse gênero é a ação, que se desenvolve diante do espectador... Personagens ${ }^{4}$ (interlocutores) agem e falam ${ }^{5}$ (interagem)...

A base desses dois gêneros retórico e discursivo é o diálogo, que se estabelece entre os interlocutores numa comunicação viva, face a face, espontânea, e de certa forma livre, visto que são escritos na intenção de serem apresentados oralmente. Esses gêneros trazem consigo uma forte influência da língua falada ou conversação propriamente dita, de forma que suas transmissões abrangem especificamente o aspecto oral da língua, embora tenham forma escrita e instruções a serem seguidas. Tais textos transpõem o aspecto escrito, sendo enfático o aspecto oral ou mundo da fala, isso se justifica pela interação que há entre os interlocutores na conversação, como por exemplo: correção de falas, assalto e tomadas de turnos, truncamentos, sobreposição de vozes, passagem de turnos, repetições de frases, estruturas e idéias, uso constante dos marcadores discursivos característicos de conversação espontânea, dentre outros aspectos discursivos que há na correlação entre esses dois gêneros e a conversação espontânea. Assim, defendemos que o gênero dramatização recebe incorporação da língua falada de forma enfática, ou melhor, esse gênero nada mais é do que texto escrito com formato de oralidade.

\section{DISCUSSÃO DO CORPUS}

O exemplo revela situação em que fora apresentada uma dramatização na Escola Mário Gomes de Barros, localizada no município de Novo Lino - AL, por uma 8ª série, na ocasião de uma Gincana de temas juninos, o texto transcrito faz parte de um corpus que contém oito dramatizações e pode ser encontrado no arquivo da referida escola.

$\begin{array}{ll}4 & \text { Grifo nosso. } \\ 5 & \text { Grifo nosso. }\end{array}$


O locutor 1, que é um pai de família caipira, inicia a dramatização chamando por Maria que é a mãe da família pedindo que essa acorde. A maneira como ele o faz é bem expressiva, pois, denota uma ênfase que esse dar ao nome Maria, o que percebe um prolongamento na silaba RIA. L1 acorda Maria (L2), que sai acordando a todos da casa para o início de mais uma dia na vida daquela família de camponeses.

L1 é identificado como o responsável da casa ou pai da família (na primeira parte do gênero textual em estudo) pela relação de poder (Santos, 1999) que tal informante exerce em relação aos demais que o cerca. Tendo em vista que sua posição de comando é acatada por todos sem que haja menor discussão por parte dos demais informantes, percebe-se, nesse contexto, o que disse Van Dijk (apud Santos 1999) sobre o poder estar relacionado à força, à autoridade, à coerção, à persuasão, à manifestação, ao prestígio e à posição social ocupada pelo indivíduo no grupo, na classe social ou instituição a que pertence. Como se percebe nos fragmentos abaixo:

L1 - MaRIA, MaRIA, acorda Maria.

L1 - Maria, acorda os mininos que ta na ora de ir trabalhar.

((conversas entre os ouvintes))

L2 - Acorda...()

L1 - Tomé:: Você/ você vai adquirir o comer pra gente. Viu ? Pode ir.

L1 - João Manoel vai/..vai buscar um feixe de lenha pra fazer fogo...

L1 - Você Joaquim, pode ir pro corte de cana.

L1 - Cê faça o fogo, cuide de/ de comida pro minino, que vou pra roça mai

Maria.

L3 - Tá certo painho.

L1 - Bota uma bolachinha pro minino, (atiça) o fogo no café e deixa o mi(minino).

L4 - Tá certo painho:::

O que justifica a razão pela qual ao longo do texto é enfatizado a fala de $L 1$, enquanto que L2 quase não fala, por ser a mulher, vista como uma pessoa submissa ao seu marido (senhor), não discute, apenas obedece, o que tipifica a vida das pessoas (mulheres) pertencentes a essa classe social.

Além dos aspectos apresentados nesse texto transcrito de uma dramatização, iremos encontrar outros resquícios que o identifica como sendo um texto oral, como também a interação discursiva nele existente. Como por exemplo, repetições de termos ou estruturas sintáticas, truncamentos, sobreposição de vozes, usos de marcadores discursivos, assaltos e tomadas de turnos, prolongamento de sílabas, passagem de turno, dentre outros elementos constitutivos de um texto conversacional. Um dos elementos discursivos mais usados nesse G.D estudado é a repetição como, por exemplo, na linha 1, 5, 19, 20, 21, e 23, vejamos: - Maria, Maria - L5 - Eu matei painho!! , Matasse o que Tomé? e Matou Tomé?

$\mathrm{Na}$ linha 1 e 5 houve a repetição de palavras, o que justifica a ênfase que o L1 queria dar quando chamava Maria (L2), pois o mesmo desejava que L2 respondesse aquele comando e estivesse pronta a executar outro que era levantar e acorda os meninos para irem à roça. Já os outros exemplos definem outra estratégia por parte dos interlocutores, isto pelo fatos de que as repetições que eles fazem é com intenção de reafirmar argumentos, o que como foi mostrado no segmento acima, o objetivo das 
repetições é promover a reafirmação do argumento expresso nas linhas 19, 20, 21 e 23.

A repetição é uma das estratégicas fundamentais para instalação da alocução, que promove acima de tudo a intercâmbio. Bem como se ressaltará, a repetição será abordada nesta pesquisa a partir de um conceito vasto, compreendendo não só as repetições de subsídios lingüísticos, como de estruturas e até certos tipos de paráfrases.

A fim de abalizar o procedimento da repetição na presente indagação serão ponderados os estudos de Marcuschi : "A repetição na língua falada e sua correlação com o tópico discursivo" (1990) e "A repetição na língua falada como estratégia de formulação textual"( In: Koch, 2002).

Conforme o Koch (op. cit., p.106), a repetição não é um simples ato metalingüístico, pois expressa algo novo, mesmo por meio de segmentos discursivos semelhantes. Funcionam como contornos estereotípicos, em situações de rituais da sociedade como nos pares de cumprimentos, agradecimento, despedidas. As repetições contribuem também para a compreensão mais rápida de palavras e expressões novas, pois quanto mais convencionalizados forem um sentido, palavra ou expressão, mais instantâneos serão seus processamentos.

Além, do processo acima comentado há outros elementos, tais como os truncamentos, sobreposição de vozes, uso de marcadores discursivos, assalto ao turno, prolongamento de sílabas, passagem de turno, dentre outros. Quanto a truncamentos, compreende-se por elementos discursivos encontrados num texto oral, os quais têm a função de paradas forçadas em uma frase ou o ato de refazer a seqüência lingüística. Outras vezes acontecem no momento em que um interlocutor por questão de dicção, tropeços nas palavras ou para corrigir o que disse, como pode ser confirmado nas linhas 5, 6 e 8.

L1 - Tomé:: Você/ você vai adquirir o comer pra gente. Viu ? Pode ir.

L1 - João Manoel vai/..vai buscar um feixe de lenha pra fazer fogo...

Maria.

L1 - Cê faça o fogo, cuide de/ de comida pro minino, que vou pra roça mai

Quanto à sobreposição de vozes entende-se, como já fora dito anteriormente, como sendo o instante em que dois interlocutores falam subitamente de uma só vez e ao mesmo tempo, o que pode acontecer de um dos envolvidos tomar realmente o turno ou desistir da tomada. É o que acontece exatamente na linha 13 e 14 do texto em estudo, em que os dois interlocutores falam em um só momento.

Graças a Deus.

Graças a Deus

Além dos elementos estudados, assalto e passagem de turno são mais dois elementos sobre os quais gostaríamos de tecer algum comentário e identificá-los no gênero em estudo. Em algum momento, o ser muito pequeno, apresenta tal característica e isso se percebe nas seguintes vozes do discurso das linhas 19 a 24 Oi Tomé. Eu matei painho!! Matasse o que Tomé? Uma galinha preta. Matou Tomé? E então (painho), tais passagens de turno são encontradas no texto por negociação 
ou livremente, visto que, os interlocutores usam marcadores discursivos que levam a estruturas de perguntas que obviamente requerem uma resposta.

\section{REFERÊNCIAS BIBLIOGRÁFICAS}

BAKHTIN, Michail. Estética da Criação verbal. São Paulo, Martins Fontes [1979]. 1992.

BARBOSA, Jacqueline Peixoto, Um perspectiva enunciativa para o ensino de Língua Portuguesa (Tese de Doutorado). São Paulo. LAEL/PUC.

BRANDÃO, Helena Nagamine (org). Gêneros do discurso na escola, 2 ed. São Paulo, Cortez. 2001.

CASTILHO. Ataliba Texeira de. A lingua falada no Ensino de Português. São Paulo. Contexto, 1998.

DOLZ e SCHENEUWLY, B. Genres et progressio em expression orale et écrite : elements de réflexion à pros d'une experince romande. Enjeux. Tradução de Roxane Rojo, (1996)

DOLZ e SCHENEUWLY, B.Os Gêneros escolares- das prática de linguagem aos objetos de ensino.Tradução de G.S. Cordeiro. Revista Brasileira de Educação, 11 maio/agosto. 1997.

GRAFF, Harvey J. Os labirintos da alfabetização, Porto alegre, Artes Médicas, 1995.

HALLIDAY, M.A.K. (1985) An Introduction to Functional Grammar. London.

HALLIDAY, M.A.K. e HASAN, R. (1985) Language, Context, and Text: Aspects of Language in a Social-Semiotic Perspective. Oxford. Oxford University Press.

KOCH, I.G.V. (1987) Argumentação e Linguagem. São Paulo,Cortez Editora. 1987.

$\mathrm{KOCH}$, I.G.V. A inter-ação pela linguagem. São Paulo: Contexto, 1993. KOCH, I.G.V. e Travaglia, L.C. A Coerência Textual. São Paulo. Editora Contexto. 1990.

MARCUSCHI, L.A. Da fala para a escrita: atividade de retextualização- $4^{\mathrm{a}}$ ed São Paulo, Cortez, 2003.

A repetição na língua falada e sua correlação com o tópico

discursivo. Recife, UFPR, 1990, (mimeo).

A repetição na língua falada: formas e funções. Recife,Universidade

Federal de Pernambuco - Departamento de Letras, 1992, (mimeo).

A repetição na língua falada como estratégia de formulação textual.

In: $\mathrm{KOCH}$, Ingedore G. Villaça (org.) Gramática do português falado. 2. ed. rev . Vol.

VI : Desenvolvimentos, Campinas, Editora da Unicamp,2002.

RAMOS. Jania M. O espaço da oralidade na sala de aula. São Paulo Martins Fontes. 1997.

ROJO, R.H.R. A prática de linguagem em sala de aula: Praticando os PCN's, São Paulo. EDUC. Campinas: Mercado das Letras.

SANTOS. M.F.O. Gêneros Textuais: Na Educação de Jovens e Adultos em Maceió, Maceió - AL, FAPEAL, 2004

SANTOS, M.F.O. Professor-Aluno, As Relações de Poder,Curitiba, PR HD Livros, 1999.

SANTOS, M.F.O. A Interação em Sala de Aula. Recife - PE, Editora Bagaço, 2004

SWALES, J.M. (1990) Genre Analysis - English in Academic and Research

Settings. Cambridge - Cambridge Iniversity Press.

TODOROV, T. Os gêneros do discurso. São Paulo, Martins Fontes, 1980.

LINS, Neilton Farias. Gêneros Discursivos e o Ensino de Linguagem. Revista

Eletrônica de Divulgação Científica em Língua Portuguesa, Lingüística e Literatura Letra Magna. Ano 04 n.06-1ํ Semestre de 2007. [www.letramagna.com.br]. 


\section{PDF created with pdfFactory trial version www.pdffactory.com}

